\title{
(Research Article) \\ Design and Analysis of Hydraulic Jack with Different Gear Mechanisms
}

\author{
G. K. DIXIT ${ }^{1^{*}}$ \\ ${ }^{I *}$ Student,Department of mechanical Engineering, B.H.Gardi institute of Engineering \& Technology Rajkot, Gujarat, INDIA
}

\begin{abstract}
This project is based on the design and analysis of quick lifting jack with different gear arrangements. Before the new jacks the conventional jacks were operated manually and were highly time consuming and also exhausting for the operators, they have to be in prolonged squatting or bending position which tends to increase their back pain or increase getting muscle aches. Also in the industry there are different working groups of different age and for elderly person it is quite heavy work. Which leads to the invention of quick lifting jacks in which the labor of the operator is drastically reduced that increases the efficiency and reduction of time. In this project to reduce this type of labor work the design of the new hydraulic jack will be useful. In this jack there are two arrangement in gears which are bevel gear arrangement and spur gear arrangement also there is piston pump involved into it. This will provide both mechanical and hydraulic advantages into the jack.
\end{abstract}

Keywords: hydraulic jack, mechanical jack, Gear arrangements, quick lifting jacks

\section{Introduction}

The hydraulic jacks are an equipment worked out for the lifting of heavy items with Less or minimum effort. It employs the use of hydraulic power or say hydraulic fluids to lift heavy Equipment's there are mainly two types of hydraulic jacks which are used more are car jack and floor jack or garage jack. They are used in lifting and also enable the maintenance of heavy automobiles. They are rated according to their maximum lifting capacities that are ranged from 1.5 tons to 30 tons.

There are many jacks available for their high lifting capacities, high lift rate and with different power sources some of them use hydraulic power some use air as working power and some use mechanical advantage to fulfil their purpose.

It is also simple to use them once it has been used. In this current drive against automation has given us so many options to choose from the innovation of new machines, new processing techniques, new working methods with this the substitution of labor has decreased drastically and it is widely gaining popularity because of its possible advantages it can offer. Hydraulic jacks uses incompressible oil which has good lubrication properties and high stability to maintain its nature without affecting its surroundings.

${ }^{*}$ Corresponding Author: e-mail: dixitgovind042@gmail.com ISSN 2320-7590

(C) 2021 Darshan Institute of Engg. \& Tech., All rights reserved
In recent times the most of jacks are manually powered and work on lever lift system. Which is to use the mechanical advantage of pivot centered rod to lift the load. Also the mechanical jacks are heavy compared to hydraulic jacks in some points like in for lifting 1 to 2 tons of load for that it is heavier than hydraulic jack for the same lifting capacity.

The main objective of this work is to design a jack which have both the advantages of hydraulic and mechanical power to use. The other specific objectives are,

- To design a new gear arrangement for the jack.

- Analysis of the new gear arrangement.

- Design a quick lifting jack in which new gear arrangement can be used.

- Analysis of new type of quick lifting jack to withstand high load, High working efficiency and improvement in life cycle.

There are three implications done in this work for the desired output which are, implication of spur gears of different pitch diameters and with different teeth numbers and with low gear ratios for spur gears. The lower the gear ratio the higher their mechanical efficiency which can go up to $98 \%$ in some cases.

The next implication is to use modified quick return mechanism which is modified in which the last part of the mechanism slider is removed and there is link which is directly connected to the end link of piston in piston pump. 
The last implication is to use bevel gear arrangement in which there are two bevel gears attached with each other with normal to each other and with this there is power screw attached to it.

\section{History of Lifting Devices}

The history of lifting devices are of several years in which we are taking some of the devices which are useful for us for providing information on this devices.

The first one is a lifting device known as modified screw jack for industrial purposes in which the jack is powered by screw motion and it uses bevel gears for transmission of power for lifting pad. This is modified to use in industrial settings and more to be comforting in lifting loads. [1]

The second one is remote controlled hydraulic jack which is a prototype model and it can be powered by a $12 \mathrm{v}$ battery. For this it gains power from a tractor or car batteries and it can be controlled by remote from distant place. [2]

The third is about motorized automated object lifting device which is distinctively related to hydraulic lifting device in which an electrical motor is used for power transmission and there is a power screw used and small load is applied to lift or lower the load which uses mechanical advantage and electrical advantage to easily raise or lower the load.[3]

The fourth is hydraulic quick lifting jack which is improved version of the hydraulic jacks in which the modifications are done on valves of hydraulic system and oil return and fastener assembly is used to obtain the results. [4]

The fifth is removable gear drive which is based on mechanical powered jack which has telescopic tubes which can expand and contract by application of axial screw which results in motion of up and down for favorable driving of the jack the screw is mounted on a gear drive. [5]

The sixth is a circuit of hydraulic jack for a quick rise and down for lifting jack in this is done by two sets of stages in jack the first stage is the valve system is directly mounted on the base of jack and second stage is multiple valve positioning in different areas to effortlessly control and manage the control of hydraulic oil and increase the speed of lift up and down of the jack [6]

The seventh is the jack which works on air, electricity and hydraulic power which is used for landing gear in which there are modifications in which the motors can be changed to whichever the three of the powers are available for reducing the cons of the single powered jacks and it does not change the jack a bit. Each motor drive output is connected to the input shaft which drives the worm gear which improves work efficiency and distributing the loads between the three motors. [7]
The eighth is quick rise hydraulic lifting jack it uses two types of actuators hydraulic and mechanical actuator which are ratchet mechanism and articulated linkage which can be used for push bar, pull bar and pivot link and the lifting is done by ratchet mechanism that works by push bar operated by lift arm which makes an half parabola movement and lifts load. [8]

The ninth is load settable rapid lifting jack which as per load application changes the oil chambers if the load is big then it changes to pump oil chamber and for lower loads it changes to inner oil tank. In inner oil tank the oil is limited and also used for switching piston as the oil changes from one chamber to another chamber. [9]

The last is low cost vehicle jack the jack is of normal working capacity and load lifting range but the modifications are done in the safety and low cost division by having hole formed in the rear wall and formation of hollow rectangular tube in leg housing. [10]

\section{Design of Components}

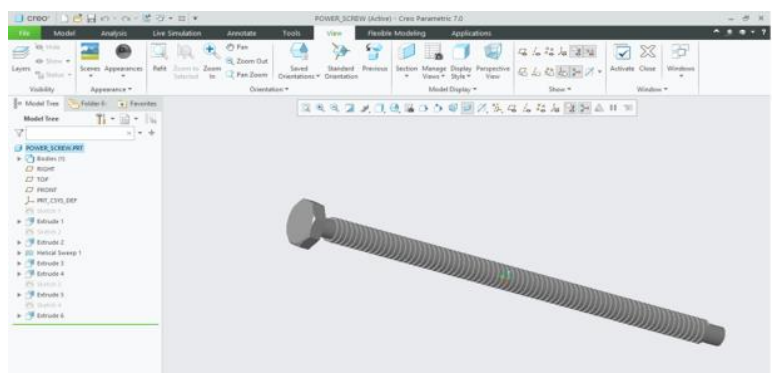

Figure 1. Design of power screw

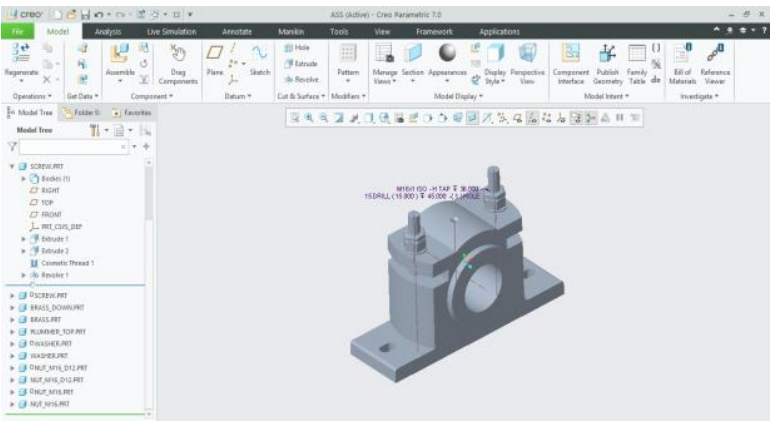

Figure 2. Design of plummer block

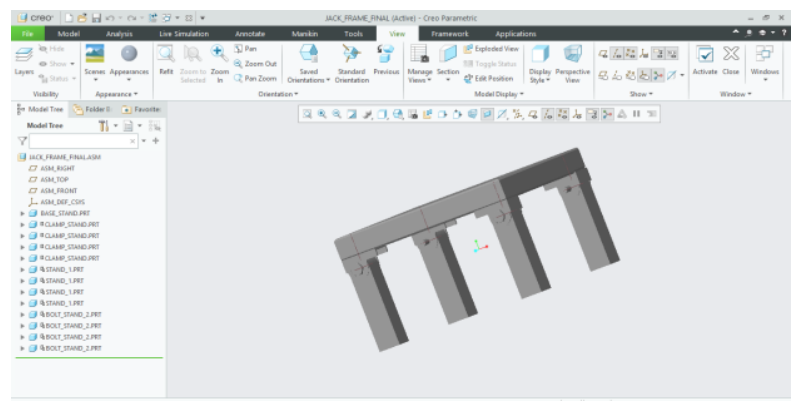

Figure 3. Design of jack frame and stand 


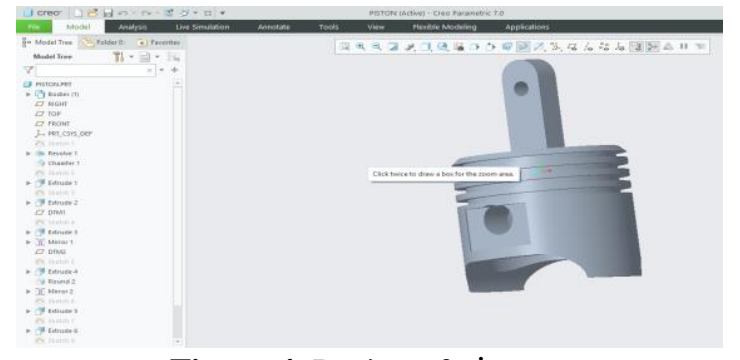

Figure 4. Design of piston

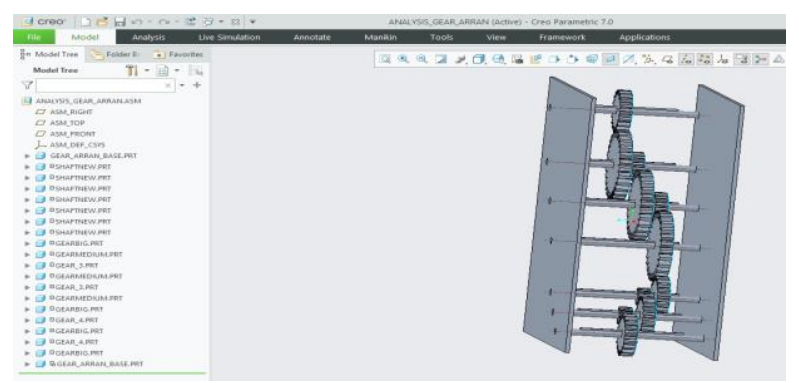

Figure 5. Design of gear arrangement

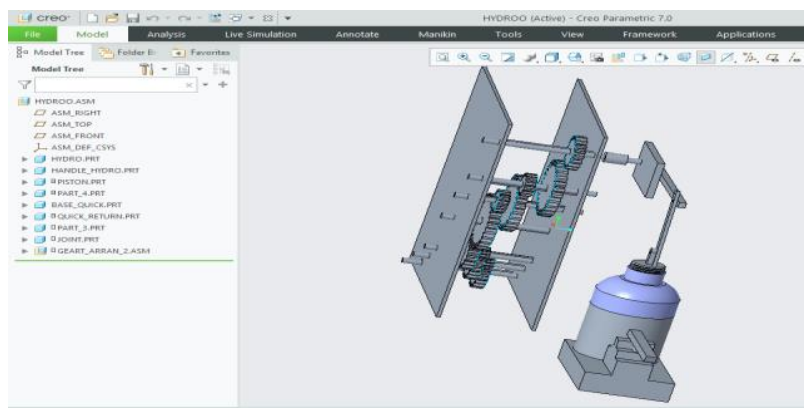

Figure 6. Design of hydraulics

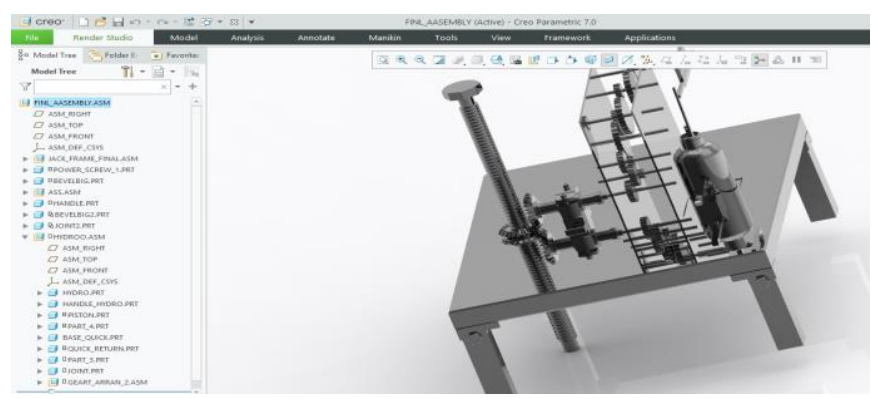

Figure 7. Final design of jack

3.1 Materials for Jack: For Jack frame the material is used is mild steel equivalent to grade AISI 1008.

\section{Composition:-}

This steel contains,

Table. 3.1: Composition of EN 1.031 material

\begin{tabular}{|c|c|c|}
\hline Carbon & Silicon & Manganese \\
\hline $0.10 \%$ & $0.40 \%$ & $0.45 \%$ \\
\hline
\end{tabular}

It also contains small fractions of copper, nickel, chromium, aluminium and molybdenum.

\section{Properties:-}

High load resistance.

High load bearing capacity.

The columns for the stand are of the same material.

The bolts, Nuts and Washer in stand are of standard material used in making fasteners. Which is Carbon steel EN 898 with strength class of 5.6.

\section{Composition:-}

This steel contains,

Table. 3.2: Composition of EN 898 material

\begin{tabular}{|c|c|c|}
\hline Carbon & Silicon & Phosphorus \\
\hline $0.55 \% \mathrm{max}$ & $0.060 \%$ & $0.050 \%$ \\
\hline
\end{tabular}

Properties:-

High elongation rate.

High hardness.

High resilience.

3.2 Material for Power Screw: The material for power screw is made of plain carbon steel.

\section{Composition:-}

Table. 3.3: Composition of plain carbon steel material

\begin{tabular}{|c|c|c|c|}
\hline Manganese & Silicon & copper & Carbon \\
\hline $1.65 \% \max$ & $0.60 \%$ & $0.60 \% \max$ & $1.70 \% \max$ \\
\hline
\end{tabular}

Properties:-

High friction reduction.

High tensile strength.

3.3 Material for Bevel gear: The material used for bevel gears is SUS304 stainless steel.

\section{Composition:-}

Table. 3.4: Composition of SUS304 material

\begin{tabular}{|c|c|c|c|}
\hline Manganese & Silicon & chromium & Carbon \\
\hline $2 \%$ & $1.00 \%$ & 18.0 to $20.0 \%$ & $0.08 \%$ \\
\hline
\end{tabular}

Properties:-

High corrosion resistance.

Higher durability.

3.4 Material for spur gear: The material for spur gears are made of SS 304 stainless steel.

Composition:-

Table. 3.5: Composition of SS 304 material

\begin{tabular}{|c|c|c|c|}
\hline Manganese & Silicon & chromium & Carbon \\
\hline $2 \%$ & $0.75 \%$ & 17.5 to $19.5 \%$ & $0.07 \%$ \\
\hline
\end{tabular}

Properties:-

High oxidation resistance.

Higher life cycle.

3.5 Material for Plummer block: The Plummer block used in this area is non-split Plummer block and the material is same as above SS 304 stainless steel. 
3.6 Material for quick return mechanism: The material for quick return mechanism is made of SS 316 stainless steel.

Composition:-

Table. 3.6: Composition of SS 316 material

\begin{tabular}{|c|c|c|c|}
\hline Molybdenum & Silicon & chromium & Nickel \\
\hline $2 \%$ & $0.75 \%$ & $16 \%$ & $10 \%$ \\
\hline
\end{tabular}

\section{Properties:-}

Highly durable.

High corrosion resistance.

3.7 Material for piston pump: For piston pump standard material for hydraulic cylinder is taken which is plain carbon steel same as above.

\section{Calculations}

\subsection{Buckling load calculation:}

$\mathrm{F} 1=\left((\text { Working stress })^{*}(\right.$ screw cross-section area $\left.)\right) /$ $\left(1+\mathrm{a} *\left((\mathrm{~L} / \mathrm{K})^{2}\right)\right.$

Where,

i. $a=1 / 7500$ for mild and Carbon steel

ii. $\mathrm{L}=2 *$ thread length of screw

iii. $K=$ least radius of gyration $=d / 4$ where $d=$ screw core diameter

iv. Cross section area of core diameter $A=(3.14 / 4) *(d)^{2}$

v. Working stress $=$ yield stress of mild steel $=210 \mathrm{MPa}=$ $21.41 \mathrm{Kg} / \mathrm{cm}^{2}$

4.1.1 Factor of safety on buckling load:

Safe working load F2 $=1.25 *$ screw working load. Here the load to be lifted is $7000 \mathrm{Kg}$

\subsection{Calculation of pitch for screw:}

i. Rate of lift $=600 \mathrm{~mm} / \mathrm{min}$

ii. Screw rotation= $30 \mathrm{RPM}$

iii. Pitch $=$ Rate of lift $/$ Screw rotation $=600 / 30=20$

iv. Outer diameter $=2 *$ height $* \mathrm{~d}$

v. Height $\mathrm{H}=0.5^{*}$ pitch

vi. Width $\mathrm{W}=0.5 *$ pitch

\subsection{Calculations for gears:}

4.3.1 Determination of a Velocity Ratio:

Velocity ratio $=(\mathrm{N} / \mathrm{n})=(\mathrm{t} / \mathrm{T})$

where,

$\mathrm{N}=$ no. of revolutions of driver gear

$\mathrm{n}=$ no. of revolutions of driven gear

$\mathrm{T}=$ no. of teeth of driver gear

$\mathrm{t}=$ no. of teeth of driven gear

4.3.2 Allowable tooth stress:

$\mathrm{Sa}=$ endurance strength $*((3) /(3+\mathrm{V}))$

$\mathrm{V}=$ Pitch line velocity $=200 \mathrm{~m} / \mathrm{s}$

4.3.3 Permissible working stress:

$\sigma=($ Tangential load acting on the tooth $* h) * 6 / b^{*} t^{2}$

where,

i. $\mathrm{h}=$ Length of the tooth

ii. $b=$ Width of gear face iii. $\mathrm{t}=$ Tooth thickness

4.3.4 Dynamic tooth load:

$\mathrm{F}_{\mathrm{d}}=\left(\left(21 \mathrm{~V}\left(\mathrm{~b}_{\mathrm{c}}+\mathrm{F}\right) /\left(21 \mathrm{~V}+\sqrt{\mathrm{b}_{\mathrm{c}}}+\mathrm{F}\right)\right)+\mathrm{F}\right.$

i. $\mathrm{V}=$ Pitch line velocity

ii. $\mathrm{b}=$ Face width

iii. $\mathrm{C}=$ Constant which depends on the tooth form

iv. $\mathrm{F}=$ Force or Tangential load acting on the tooth

4.4 Calculation for power screw efficiency, load required to lift the load, load required to lower the load, minimum pressure:

i. $\mathrm{F} 1=\mathrm{M}^{*} \mathrm{~g}$

ii. $\mathrm{F} 1=7000 * 9.81=68670 \mathrm{~N}=68.67 \mathrm{KN}$

4.4.1 Pressure analysis:

i. $P c m=\mathrm{F} 1 / A c$

ii. $A c=3 \cdot 14^{*} \mathrm{D}_{\mathrm{Ci}}{ }^{2 / 4}$

$\mathrm{Dci}=$ Diameter of internal cylinder.

$P c m=$ minimum cylinder pressure.

4.4.2 For power screw thread:

The thread here used is square thread.

A. Helix angle of power screw thread:

i. $\operatorname{Tan} \propto=\mathrm{P} / 3.14^{*} \mathrm{Dm}$

ii. $\propto=(1 / \tan ) * 20 / 3.14 * 72=5.055^{\circ}$

Where,

$\mathrm{P}=$ lead=pitch of square thread.

Dm = Diameter of screw.

$B$. For frictional angle:

i. $\emptyset=1 / \tan * \mu$ for steel $\mu=0.15$

ii. $\emptyset=1 / \tan * 0.15=8.53^{\circ}$

Here the angle of friction is higher than helix angle so the power screw is self-locking type.

4.4.3 For Efficiency of thread:

Efficiency of thread $=$ ideal effort/actual effort $=W o / W$ a

4.4.4 For lowering the load force required:

i. $W$ lower $=F 1 * \tan (\emptyset-\propto)$

ii. $W$ lower $=68670 * \tan (8.53-5.055)$

iii. $W$ lower $=4169.96 \mathrm{~N}$ load is required to lower the load of $7000 \mathrm{~kg}$

4.4.5 For raising the load force required:

i. $W$ raise $=F 1 * \tan (\emptyset+\propto)$

ii. $W$ raise $=68670 * \tan (8.53+5.055)$

iii. $W$ raise $=16593.99 \mathrm{~N}$

4.4.6 Efficiency:

i. $\eta=(\tan \propto / \tan (\varnothing+\propto)) * 100$

ii. $\eta=(\tan 5.055 / \tan (8.53+5.055)) * 100$

iii. $\eta=36.60 \%$

4.4.7 Maximum thread efficiency:

i. $\eta m=(1-\sin \emptyset) /(1+\sin \emptyset)$

ii. $\eta m=(1-\sin 8.53) /(1+\sin 8.53)$

iii. $\eta m=0.742 * 100=74.2 \%$

4.4.8 Torque required to Raise the load:

Torque $=\mathrm{P}^{*}(\mathrm{~d} / 2)$, where $\mathrm{P}=\mathrm{W}$ tan $(\emptyset+\propto), \mathrm{l}=712 \mathrm{~mm}$

$=2 * 1 /\left(\mathrm{d}^{*} \tan (\varnothing+\propto)\right)=2 * 712 /(82 * \tan (5.055+8.53))=$ 71.88 N.MM.

4.4.9 Torque required to reduce friction:

$\mathrm{T} 1=\mathrm{F} 1 * \tan (\emptyset-\propto) *(\mathrm{~d} / 2)=67680 * \tan (8.53-5.055)=168.50$ 
N.MM.

\section{Analysis}

5.1 Motion Analysis of part 1

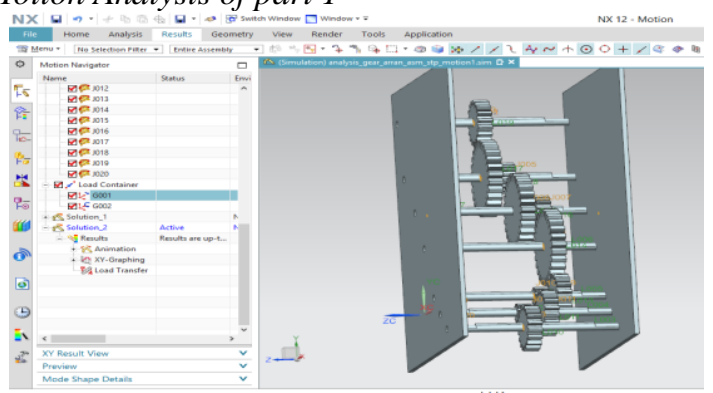

Figure 8. Motion analysis of part 1

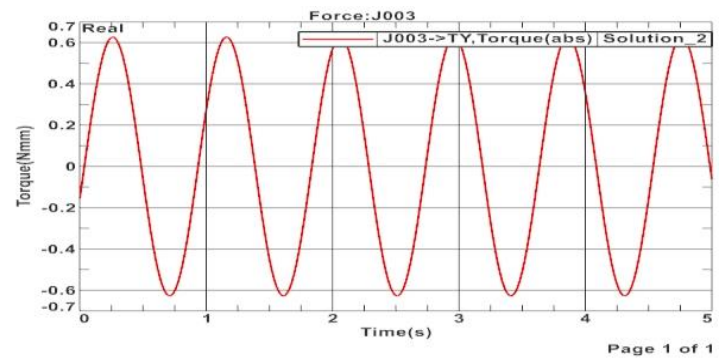

Figure 9. Graph of torque vs. Time

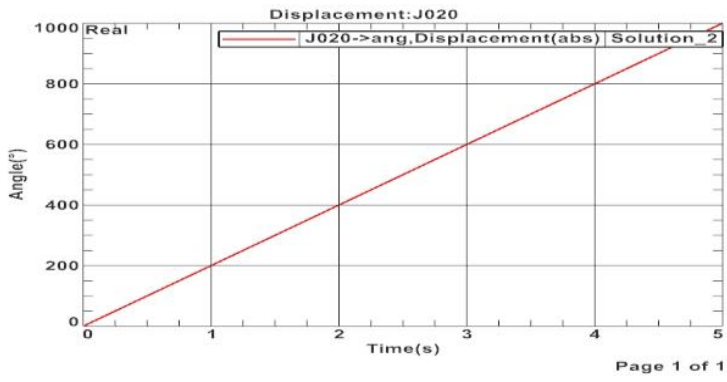

Figure 10. Graph of angle vs. Time

Description:

The motion analysis of the above part shown in Figure. 8 is given in graph form which are torque and angle vs. time for different joints.

The above part has several spur gears meshed with each other and there are seven shafts connected to side plates for support and in both side plates there are holes for shaft connecting.

The shafts are connected to plates then the gears are lined with each other by fitting them through key ways provided in shafts.

After that each of the shafts are given movement which is rotation in respective direction and applying torque on each shafts.
The above graphs are taken from the joints created in nx by motion simulation and analysis from the same perspective and method the second graph is taken the angle from which the rotation is given

\subsection{Motion Analysis of part 2}

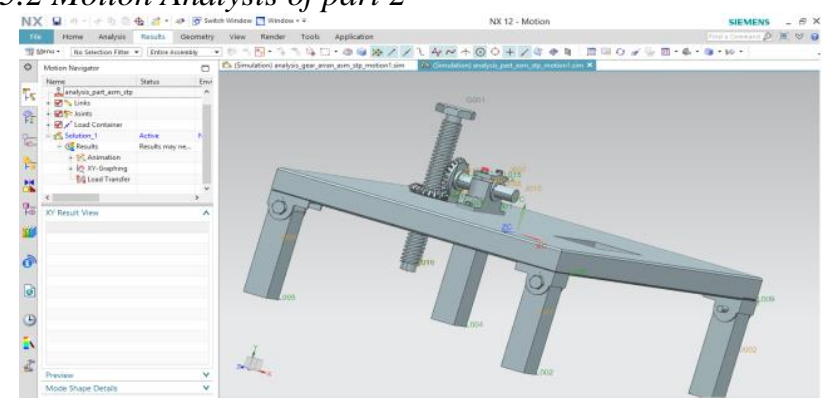

Figure 11. Motion analysis of part 2

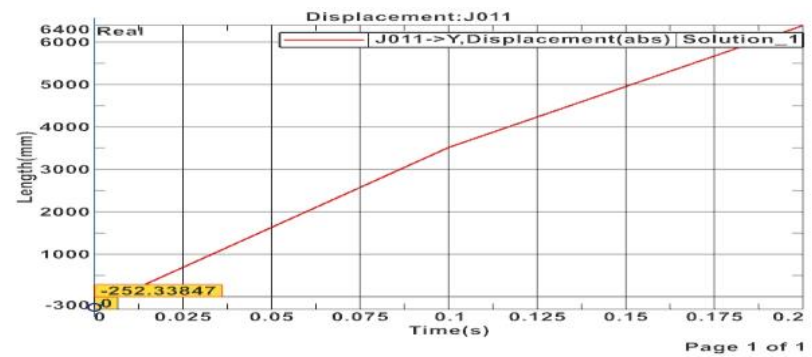

Figure 12. Graph of Length vs. Time

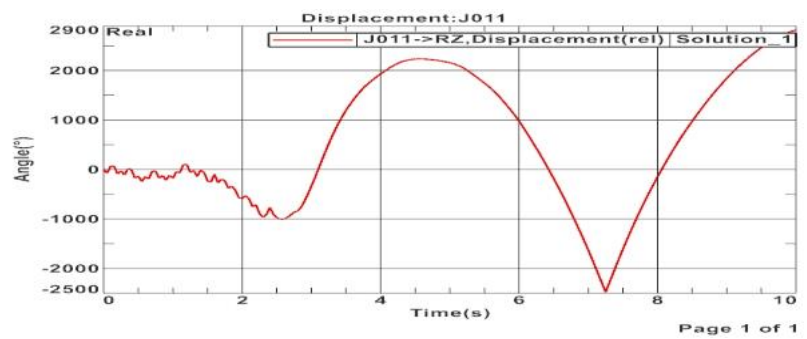

Figure 13. Graph of angle vs. Time

\section{Description:}

The motion analysis of the above part shown in Figure. 11 is given in graph form

For the first graph length vs. time is about how much time it takes power screw to pass through the jack base here the power screw length is $700 \mathrm{~mm}$ and the graph starts from -300 $\mathrm{mm}$ so it shows rising as the time passes.

The second is about angle vs. time which is the pressure angle for the square thread provided in jack base it comes from there the meshing of power screw and the thread in base happen at an angle which is why the angle is there. It starts with 0then goes down at first half then it starts to rise in second part and then it again goes up. 


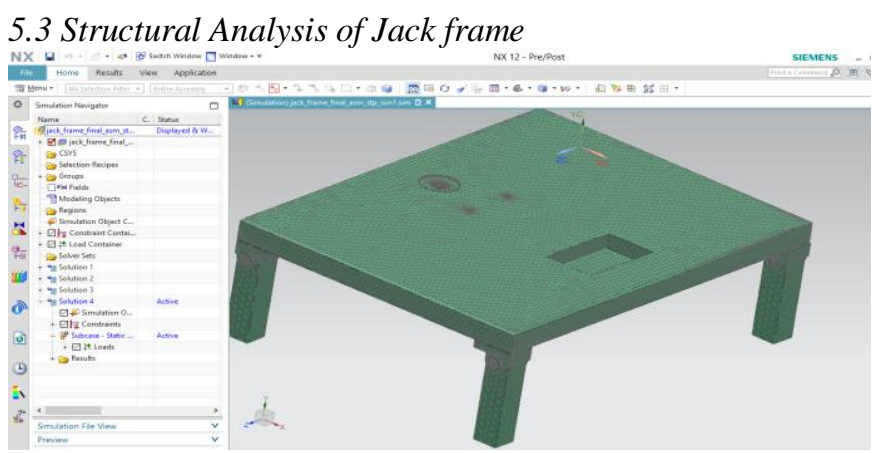

Figure 14. Structural analysis of jack frame.

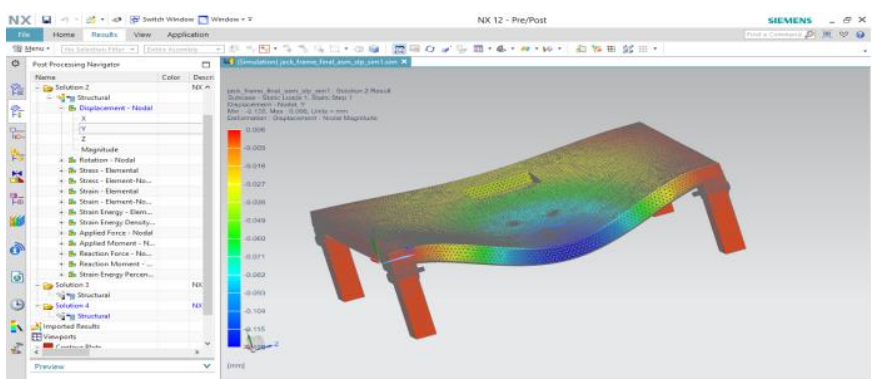

Figure 15. Displacement on $\mathrm{Y}$-axis for $7000 \mathrm{~kg}$

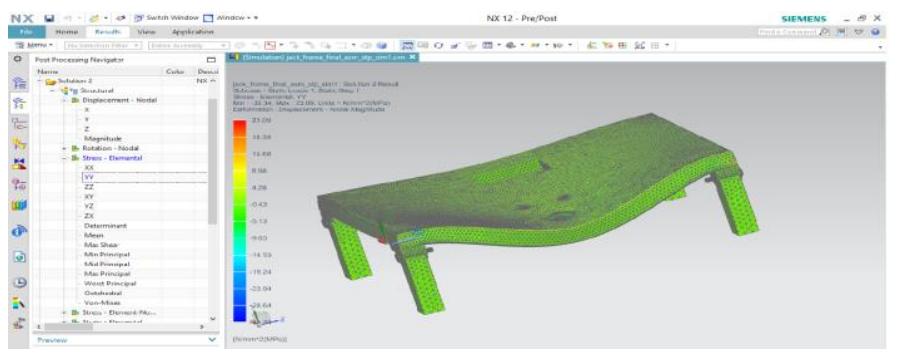

Figure 16. Stress on Y-axis for $7000 \mathrm{~kg}$

\section{Conclusion}

We have successfully completed the design part for the jack in CREO 7.0 and NX 12.0 and have done analysis of the jack in NX 12.0.

Further For the part of the analysis we have done two analysis which is motion simulation analysis resulting in graphs shown above and second is structural analysis shown in form of images.

The results of both analysis have been given with varieties in different values of the entities terms as torque, force, velocity, length, angular velocity and time and it is in expected range.

\section{References}

1. Ezurike, Benjamin, and Modestus Okwu. "Modified Screw Jack for Lifting Operation in Industrial Setting." Int. J. Engr. \& Techn 13 (2017): 39-50.
2. Sivaraj, P., A. R. Tamilarasan, R. Vignesh, P. Uthaya Prabakaran, and M. Sivaraja. "REMOTE CONTROLLED HYDRAULIC JACK.

3. Rout, Ivan Sunit, Dipti Ranjan Patra, Sidhartha Sankar Padhi, Jitendra Narayan Biswal, and Tushar Kanti Panda. "Design and Fabrication of motorized automated Object lifting jack." IOSR journal of engineering (IOSRJEN) ISSN (e) (2014): 2250-3021.

4. Hung, Michael. "Hydraulic quick lifting unit of a jack." U.S. Patent 6,035,635, issued March 14, 2000

5. Straw Sr, Shane A., and Christopher M. Morris. "Removable gear drive for mechanical jack." U.S. Patent 6,446,937, issued September 10, 2002.

6. Wixey, Matthew A. "Simplified hydraulic circuit for a quick-rise hydraulic lifting jack." U.S. Patent 6,581,909, issued June 24, 2003

7. Daniel, Jeffrey. "Air, electric and hydraulic landing gear jack." U.S. Patent 6,926,305, issued August 9, 2005

8. Hung, Victor. "Load-settable rapid lifting jack." U.S. Patent Application 10/052,272, filed July 24, 2003

9. Tatsumi, Kimio."Quick rise hydraulic lifting jack."U.S. Patent 7,055,801, issued June 6, 2006

10. Alvarado, Daniel. "Low cost vehicle safety jack." U.S. Patent Application 09/726,209, filed December 20, 2001.

11. C.A. Okoronkwo et al., Design of a hand water pump using a quick-return crank mechanism, African Journal of Science, Technology, Innovation and Development. 8(3) (2016) 292-298

12. I.S. Rout et al., Design and fabrication of motorized automated object lifting jack, IOSR Journal of Engineering. 04(05) (2014) 6-12

13. K.R. Mounika, C.H. Priyanka, Design and fabrication of motorized screw jack for four wheeler, A Project Report, Department of Mechanical Engineering, Gokaraju Rangaraju Institute of Engineering and Technology, 2011

14. Muchnik, J., (2007)History of Hydraulic Jacks,Ezine Publisher, New York;

15. R.S. Khurmi, J.K. Gupta, Textbook of Machine Design, Eurasia Publishing House, Ram Nagar, New Delhi, India, 2005

\section{Softwares Used}

1. PTC CREO 7.0

2. Siemens's NX 12.0 